\title{
Formation of texture and anisotropy of shape memory effect in Fe-Mn-Si-Co-Cr alloy
}

\author{
K.K. Jee, J.O. Song ${ }^{1}$, W.Y. Jang ${ }^{2}$, M.C. Shin and C.S. Choi ${ }^{1}$ \\ Division of Materials, Korea Institute of Science and Technology, Seoul 136-791, Korea \\ ${ }^{1}$ Department of Metallurgical Engineering, Yonsei University, Seoul 120-749, Korea \\ 2 Department of Metallurgical Engineering, Chosun University, Kwangju 501-759, Korea
}

\begin{abstract}
This study is aimed at investigating the anisotropy of shape memory effect in Fe-based alloy. An $\mathrm{Fe}-15 \mathrm{Mn}-3 \mathrm{Si}-4 \mathrm{Co}-5 \mathrm{Cr}$ alloy is cold rolled by $92 \%$, and annealed at $630^{\circ} \mathrm{C}$ for $45 \mathrm{~min}$. The alloy undergoes $\gamma \rightarrow \varepsilon \rightarrow \alpha$ ' transformation by cold rolling and $\gamma$ is restored with a major preferred orientation of (110) $\gamma[001] \gamma$ by the annealing. The specimens for shape memory effect and tensile test are taken $0,45,70,80$ and 90 degs to the rolling direction. The specimen taken along 70 degs to the rolling direction exhibits the best shape memory effect. An analysis of the $(110) \gamma[001] \gamma$ texture reveals that the specimen experiences the deformation stress along [221] $\gamma$ which is the most expandable direction in the $\gamma \rightarrow \varepsilon$ transformation. In tensile test, the best SME specimen shows the lowest yield stress, indicating that the transformation take place most easily since the deformation is applied to the preferential direction to the transformation.
\end{abstract}

key words; shape memory effect, texture, Fe-based alloy, martensitic transformation

\section{INTRODUCTION}

Since the discovery of shape memory effect (SME) in Fe-based alloys, the alloys have drawn great attention due to advantage of low cost and good mechanical properties over non-ferrous alloys [1,2]. The alloys, however, exhibit a poor SME for commercial application. Therefore a number of studies, such as control of alloy composition [3-6] or the training [7], have been carried out to improve SME.

In single crystals, it has been reported SME differs as many as 20 times according to deformation direction in $\mathrm{NiAl}$ alloys [8]. Sato et al [2] also observed that an excellent SME is found when an Fe-Mn-Si single crystal is elongated along [441] $\gamma$ direction, because it is favorable for $\gamma(\mathrm{fcc}) \rightarrow \varepsilon$ (hcp) transformation. Therefore an excellent SME can be obtained in single crystals by taking the specimen so that the deformation direction is parallel to the best SME direction.

Though the commercial application of single crystals is limited due to price, as an alternative, it is possible to obtain the effect by controlling texture in polycrystals. Some studies revealed that SME depends on cut angle in rolled NiTi [9] and $\mathrm{Cu}-\mathrm{Zn}-\mathrm{Al}$ alloys [10].

The purpose of this study is to investigate the anisotropy of SME and to explain the mechanism by cold rolling an Fe-based shape memory alloy.

\section{EXPERIMENTALS}

An $\mathrm{Fe}-15 \mathrm{Mn}-3 \mathrm{Si}-5 \mathrm{Cr}-4 \mathrm{Co}$ alloy was chosen due to its good workability at room temperature which enables us to obtain a strong texture. The alloy was prepared by melting in a magnesia crucible in a vacuum induction furnace. The ingot was homogenized at $1000^{\circ} \mathrm{C}$ for $2 \mathrm{hr}$ and hot rolled. The plate was cold rolled with a reduction thickness of $92 \%$ before heat treated at $630^{\circ} \mathrm{C}$ for $45 \mathrm{~min}$.

The specimens were electrochemically thinned in a perchloric acid $(10 \%) /$ acetic acid $(90 \%)$ to remove the mechanical polish-affected region. $\mathrm{Cu}-\mathrm{K} \alpha$ line $(\lambda=1.542 \mathrm{~A})$ was used with a monochrometer attached. 


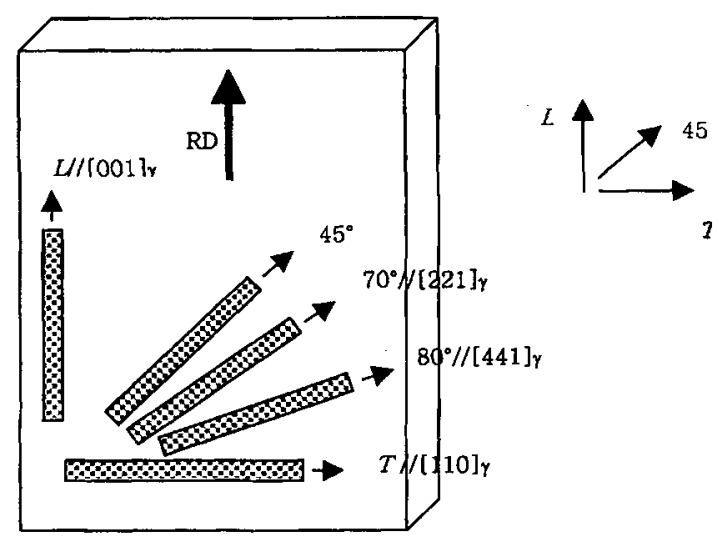

Figure 1 : Method of taking samples to examine anisotropy of SME and tensile property

The samples for SME were taken along 0 (RD), 45, 70, 80 and 90deg (TD) to the rolling direction to examine its anisotropy as in Fig. 1. The direction indices are the result of the texture of $\gamma$ phase which will be discussed later. The specimens ( $70 \mathrm{~mm}$ in length, $3 \mathrm{~mm}$ in width and $1.5 \mathrm{~mm}$ in thickness) were deformed by bending around a tube before heated above Af temperature. SME was calculated using the equation in Fig. 2.

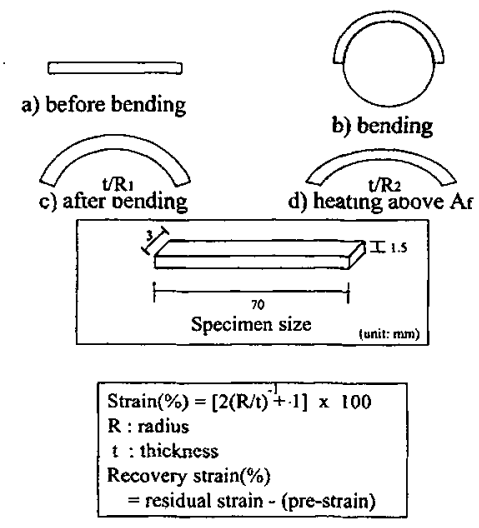

Figure 2 : Schematic illustration of SME measurement

The specimens for tension test, taken the same way as the SME specimens, have a gauge length of $12.5 \mathrm{~mm}$. Tensile test were carried out at a cross-head speed of $1 \mathrm{~mm} / \mathrm{min}$.

\section{RESULTS AND DISCUSSION}

Fig. 3 shows the variation in X-ray diffraction patterns with cold rolling degree. Small amount of $\varepsilon$ and $\alpha^{\prime}$ martensite which form on cooling exist in $\gamma$ matrix. $\gamma \rightarrow \varepsilon$ and $\varepsilon \rightarrow \alpha$ ' transformation take place concurrently by cold rolling. Only $\alpha$ ' martensite remains at a cold rolling degree of $70 \%$. 


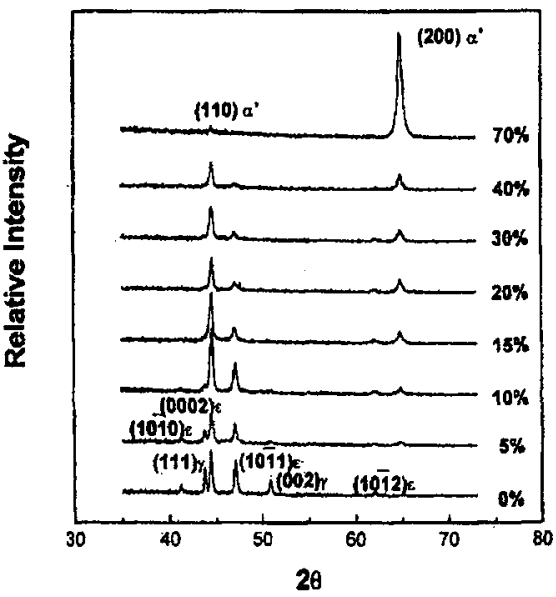

Figure 3 : Variation in $\mathrm{X}$-ray diffraction patterns with degree of cold rolling

Fig. 4 is the ODF (orientation distribution function) for $92 \%$ cold rolled plate, indicating that texture of (111) $\alpha^{\prime}[112] \alpha^{\prime}$ develops.

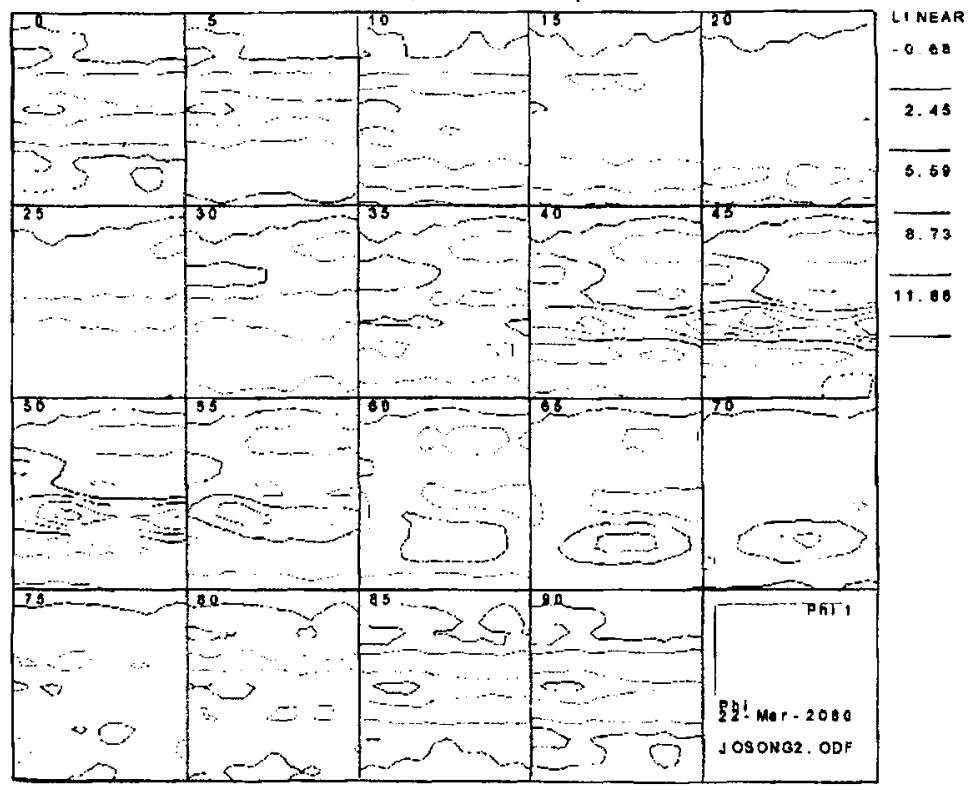

Figure 4 : ODF( $\alpha^{\prime}$-martensite) of the alloy subjected to $92 \%$ cold rolling

The cold rolled plate is heat treated at $630^{\circ} \mathrm{C}$ for $45 \mathrm{~min}$, by which $\alpha^{\prime}$ martensite transforms to $\gamma$ phase. The ODF in Fig. 5 indicates that the major texture of the reversely-transformed $\gamma$ is $(110) \gamma[001] \gamma$ and TD corresponds to $[110] \gamma$. The interpretation of the texture leads to the result that most of the grains are oriented as in Fig. 1. 


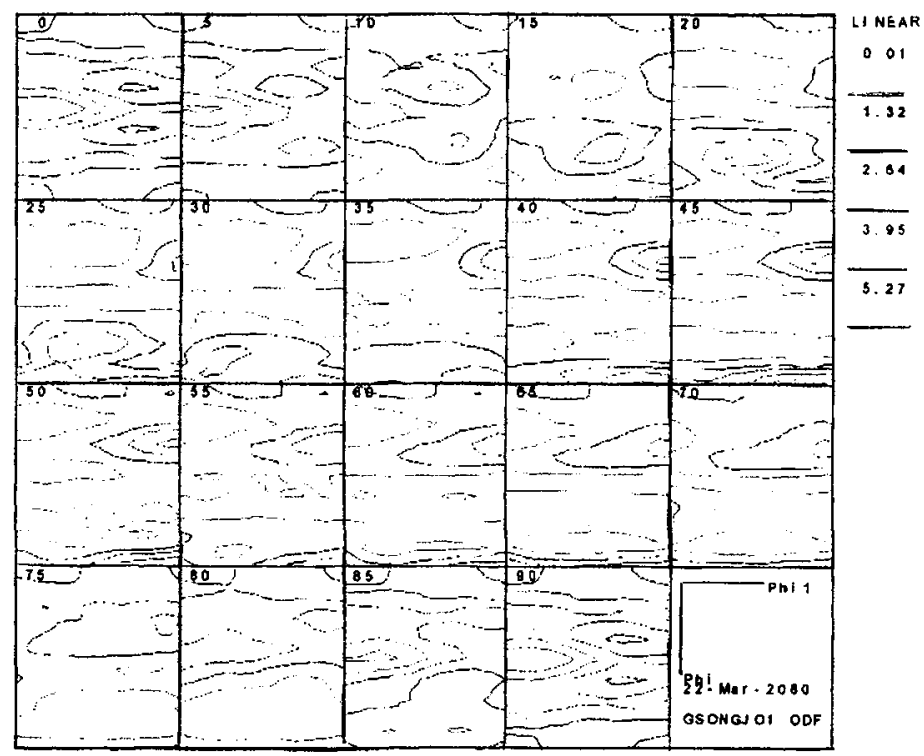

Figure 5 : ODF( $\gamma$-austenite) of the alloy subjected to cold rolling and subsequent heating at $630^{\circ} \mathrm{C}$

Figure 6 represents SME of the specimens taken along 0,45, 70, 80, 90 degs to the rolling direction. The specimen of 70 degs to the $R D$ shows the best SME at all pre-strain. The recovery rate of $R D$, the worst direction, amounts merely to $2 / 3$ of that the best direction. The recovery rate of all the specimens, as a whole, decreases abruptly at a pre-strain of $2.5 \%$, which is attributed to the $\varepsilon \rightarrow \alpha^{\prime}$ transformation [12].

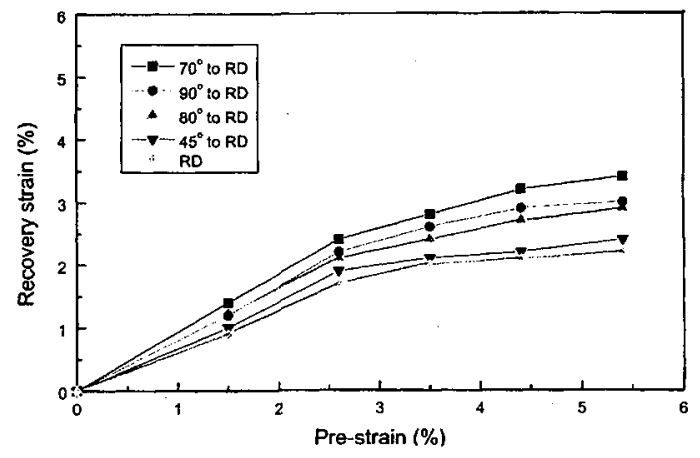

Figure 6 : Anisotropy of SME

The reason for the anisotropy of SME can be explained as follows. To clarify how the movement of $\gamma / \varepsilon$ boundaries produces external strain, we first consider strain field built by the formation of $\varepsilon$ martensite [11]. the fcc-hcp transformation takes place, as shown in Fig. 7, by the simple shear on (111) $\gamma \|(0001) \varepsilon$ planes to [112] $\|[1010] \varepsilon$ directions, which has 12 variants. 


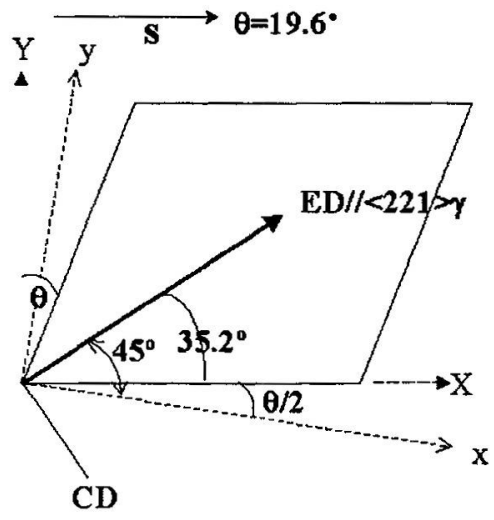

\section{$\mathrm{X} \|[\mathbf{i} \mathbf{i} 2 h \|[\mathbf{i} 010] \mathbf{s}$ $\mathbf{Y} \|[\mathbf{i} \mathbf{i} \mathbf{i}\} \boldsymbol{\|}[\mathbf{0 0 0 1}] \mathrm{E}$ $\mathrm{Z}\|[\mathbf{1} \mathbf{i} 0\}\|[\mathbf{i} \mathbf{2} \overline{\mathbf{1}}$ ]}

Figure 7 : Lattice deformation produced by $\mathrm{z}-\varepsilon$ transformation

The resulting shear strain of this alloy is $\tan 19.6 \mathrm{deg}$. The simple shear on the $\mathrm{x}-\mathrm{y}$ coordinate is equivalent to the pure shear on the $x^{\prime}-y^{\prime}$ coordinate rotated 9.8 deg clockwise. The largest elongation takes place in the

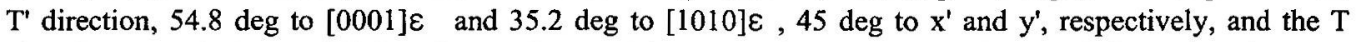

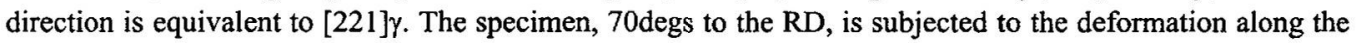
[221] $\gamma$ which experiences the largest expansion in $\gamma \rightarrow \varepsilon$ transformation. Therefore deformation along [221] $\gamma$ causes the transformation to occur most easily, exhibiting the best SME.

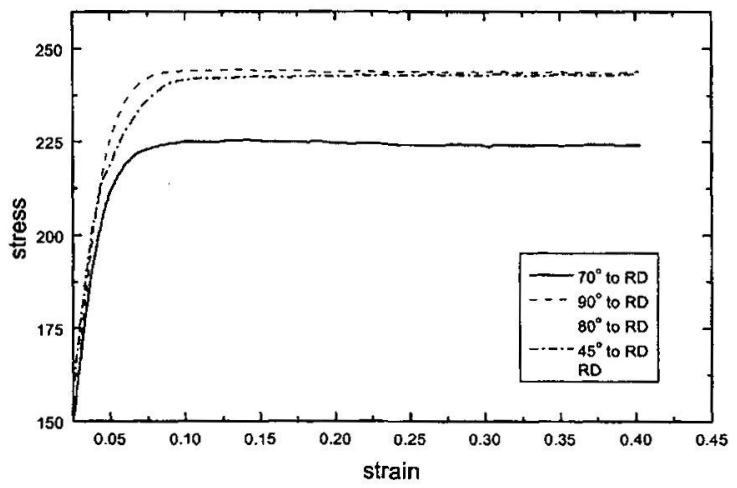

Figure 8 : Variation of stress-strain curves with specimen orientation

Fig. 8 represents stress-strain curves for the specimens taken along various directions. No strain hardening after the yield point indicates that the deformation occurs through the martensitic transformation. The specimen with a better SME exhibits a lower yield strength. The specimen along 70 degs to the RD shows the lowest yield strength, supporting the idea that deformation along [221] $\gamma$ causes $\gamma \rightarrow \varepsilon$ transformation to take place more easily than other directions. 


\section{CONCLUSION}

The study on the formation of texture and its effect on anisotropy of SME in an Fe-15Mn-3Si-4Co-5Cr alloy leads to the following conclusion.

1. The alloy undergoes $\gamma \rightarrow \varepsilon \rightarrow \alpha$ ' transformation on cold rolling, developing a strong texture of (111) $\alpha$ ' [112] $\alpha^{\prime}$. After the reverse transformation by heating, the texture is changed to (110) $\gamma[001] \gamma$.

2. The specimen along 70 degs to the rolling direction exhibits the best SME, since the direction corresponds to [221] $\gamma$ which experiences the largest expansion on $\gamma \rightarrow \varepsilon$ transformation. The lowest yield strength along the direction means easy $\gamma \rightarrow \varepsilon$ transformation on deformation.

\section{REFERENCES}

1. A. Sato, E. Chishima, K. Soma and T. Mori, Acta Metall., 30, 1177 (1982)

2. A. Sato, E. Chishima, K. Soma and T. Mori, Acta Metall., 32, 539 (1984)

3. M. Murakami, H. Otsuka, H. G. Suzuki and S. Matusda, Proceedings of ICOMAT, Nara, Japan, 1996, p. 201

4. H. Otsuka, H. Yamada, T. Maruyama, H. Takahashi, S. Matsuda and M. Murakami, ISIJ international, 30, $674(1990)$

5. R. Rijian, Z. Xiumu, L. Yiyi and S. Changxi, Proceedings of the International Symposium on Shape Memory Materials, Beijing, China, 1994, 9.493

6. K. Tsuzaki, Y. Katsume, Y. Kurokawa and T. Maki, Scripta Met. and Mat., 27, 471 (1992)

7. H. Otsuka, M. Murakami and S. Matsuda, Proceedings of MRS International Meeting on Advanced Materials, Tokyo, Japan, 1988, p. 451

8. T. Saburi and S. Nenno: Proceedings of International Conference on Solid-Solid Phase Transformations, Pittsburgh, 1981, p.1455,

9. A. K. Kitamura, S. Miyazaki, H. Iwai and M. Kohl, Mater. Sci. Eng. A273, 759 (1999)

10. N. J. Park, J. of Korean Institute of Met. and Mat., 36, 1922 (1998)

11. K. K. Jee, K. Ito and M. C. Shin, ISIJ International. 34, 912 (1994)

12. W. Y. Jang, K. K. Jee, M. C. Shin and J. H. Hong, J. of Korean Institute of Met., 759 (1991) 